\title{
Characterization of Mentorship Programs in Departments of Surgery in the United States
}

Melina R. Kibbe, MD; Carlos A. Pellegrini, MD; Courtney M. Townsend Jr, MD;

Irene B. Helenowski, PhD; Marco G. Patti, MD

IMPORTANCE Mentorship is considered a key element for career satisfaction and retention in academic surgery. Stakeholders of an effective mentorship program should include the mentor, the mentee, the department, and the institution.

OBJECTIVE The objective of this study was to characterize the status of mentorship programs in departments of surgery in the United States, including the roles of all 4 key stakeholders, because to our knowledge, this has never been done.

DESIGN, SETTING, AND PARTICIPANTS A survey was sent to 155 chairs of departments of surgery in the United States in July 2014 regarding the presence and structure of the mentorship program in their department. The analysis of the data was performed in November 2014 and December 2014.

MAIN OUTCOMES AND MEASURES Presence and structure of a mentorship program and involvement of the 4 key stakeholders.

RESULTS Seventy-six of 155 chairs responded to the survey, resulting in a $49 \%$ response rate. Forty-one of 76 of department chairs (54\%) self-reported having an established mentorship program. Twenty-five of 76 departments (33\%) described no formal or informal pairing of mentors with mentees. In 62 (82\%) and 59 (78\%) departments, no formal training existed for mentors or mentees, respectively. In 42 departments (55\%), there was no formal requirement for the frequency of scheduled meetings between the mentor and mentee. In most departments, mentors and mentees were not required to fill out evaluation forms, but when they did, 28 of 31 were reviewed by the chair (90\%). In 70 departments (92\%), no exit strategy existed for failed mentor-mentee relationships. In more than two-thirds of departments, faculty mentoring efforts were not recognized formally by either the department or the institution, and only 2 departments (3\%) received economic support for the mentoring program from the institution.

CONCLUSIONS AND RELEVANCE These data show that only half of departments of surgery in the United States have established mentorship programs, and most are informal, unstructured, and do not involve all of the key stakeholders. Given the importance of mentorship to career satisfaction and retention, development of formal mentorship programs should be considered for all academic departments of surgery.

Invited Commentary page 907

Supplemental content at jamasurgery.com CME Quiz at jamanetworkcme.com and CME Questions page 996
Author Affiliations: Department of Surgery, University of North Carolina, Chapel Hill (Kibbe, Helenowski, Patti); Editor, JAMA Surgery (Kibbe); Department of Surgery, University of Washington, Seattle (Pellegrini); Department of Surgery, University of Texas Medical Branch at Galveston (Townsend).

Corresponding Author: Marco G. Patti, MD, Department of Surgery, University of North Carolina, 4030 Burnett Womack Bldg. 101 Manning Dr, CB 7081, Chapel Hill, NC 27599-7081 (marco_patti@med.unc.edu). 
$\mathrm{M}$ entorship has been recognized as a key element of career satisfaction because it has a very important influence on career guidance, research productivity, and personal development. ${ }^{1-22}$ Traditionally, mentoring has been seen as a relationship between a senior person, the mentor, and a less experienced colleague, the mentee. This relationship is both dyadic, because it is between 2 individuals (the mentor and the mentee), and hierarchical, because the mentor is usually several years older and serves as a role model, teacher, advisor, and sponsor for the younger mentee. While this classic dyad was the cornerstone of mentoring for many decades, an increasing number of academic health science universities are recognizing the need for establishing a formal and structured mentorship program, a program that must include not only the mentor and the mentee but also the department and the institution. 1,6,10,12,16,18,20,22 The department and the institution are key stakeholders who have an important role in the establishment of a mentoring program and derive substantial benefits from its success.

Given the importance of mentorship to career satisfaction and retention ${ }^{3-6,11,12}$ and that, to our knowledge, the presence and structure of mentorship programs in departments of surgery in the United States remains unknown, the goal of this study was to characterize the status of mentorship programs in departments of surgery in the United States. We hypothesized that significant variability existed among departments with respect to the structure of the faculty mentorship program and the involvement of the key stakeholders. To address this hypothesis, a survey was developed that addressed the following 6 areas: (1) mentee-mentor pairing, (2) training for mentees and mentors, (3) commitment to the menteementor relationship, (4) evaluation of the mentee-mentor relationship, (5) how failed mentee-mentor relationships are addressed, and (6) recognition of the mentee-mentor relationship. Information from this study will provide insight into mentorship programs and may help the chairs of academic departments of surgery to establish structured mentorship programs that involve all 4 key stakeholders.

\section{Methods}

\section{Study Approval}

This research project was reviewed by the institutional review board of Northwestern University, Chicago, Illinois. This research was determined to not constitute research with human participants; thus, institutional review board approval was not required.

\section{Study Design}

A survey regarding the presence and structure of a mentorship program was sent to all chairs of departments of surgery in the United States. The email list for the department of surgery chairs was obtained from the Society of Surgical Chairs membership directory, which is available online from the American College of Surgeons website. Participation in the survey was anonymous and voluntary. The invitation to respond to the questionnaire was sent by email in early July

\section{Key Points}

Question What is the status of mentorship programs in departments of surgery in the United States?

Findings Results of a survey sent to 155 chairs of departments of surgery with a $49 \%$ response rate showed that only half of departments of surgery in the United States have established mentorship programs, and most are informal, unstructured, and do not involve all of the key stakeholders.

Meaning Given the importance of mentorship to career satisfaction and retention, development of formal mentorship programs should be considered for all academic departments of surgery.

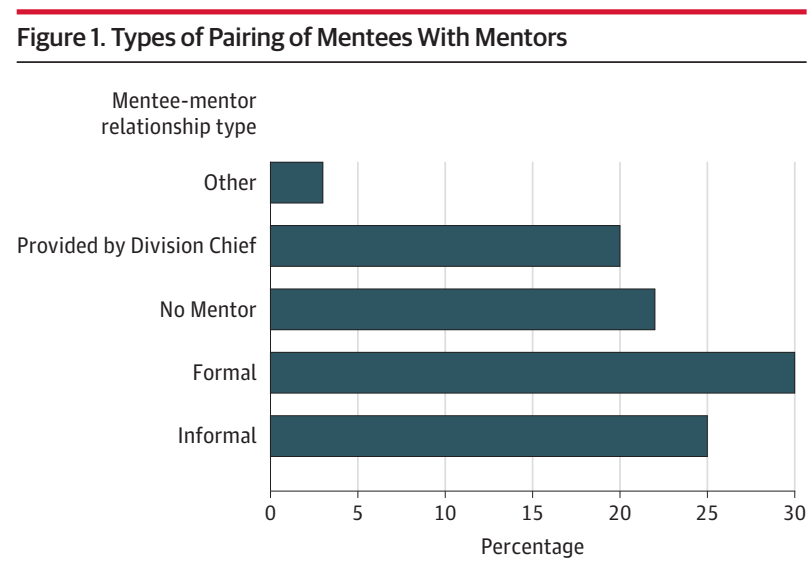

2014 to all the members of the Society of Surgical Chairs in the United States $(n=155)$. The survey response tool was set up such that each surgeon was able to respond only once to the survey. Respondents answered online using an internetbased survey tool (SurveyMonkey.com Corporation). To improve the response rate, 2 subsequent follow-up emails were sent to all members of the Society of Surgical Chairs in late July 2014 and early September 2014. In addition, all incorrect email addresses were identified and corrected, and appointment of any new chairs during the prior year were confirmed to be on the membership list and were added if they were not.

\section{Survey}

The questionnaire consisted of 19 questions regarding the presence and description of a departmental mentoring program (eAppendix in the Supplement). Most questions were either a yes/no or a multiple-choice answer. One question about a continuous variable contained a free-text answer box. The questions addressed the presence of an established mentorship program within each department and characterized the role of the 4 stakeholders (ie, mentor, mentee, department, and institution).

\section{Data Analysis}

Results presented in the article were calculated based on the number of responses received to each individual question. Thus, a nonresponse was not considered a negative answer 

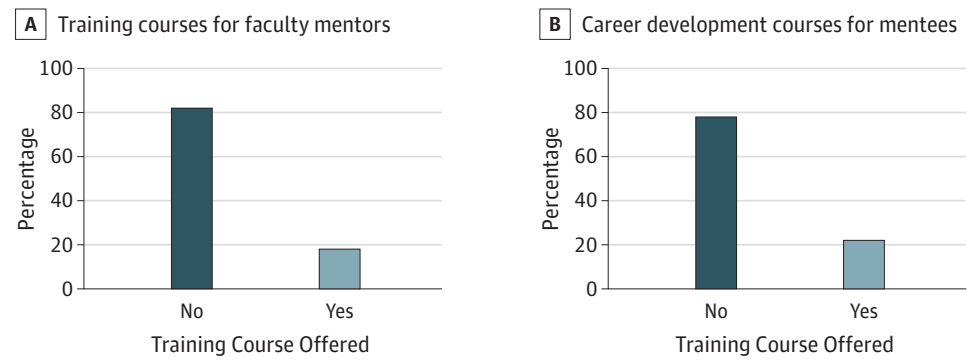

A, Percentage of departments that offer training courses for faculty mentors. B, Percentage of mentees who are required to attend career development courses.

\section{Figure 3. Exit Strategies for Failed Mentor-Mentee Relationships}

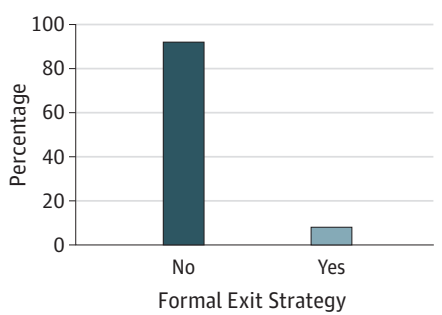

Percentage of departments of surgery that have formal exit strategies in place for failed mentor-mentee relationships.

because it was not included in the numerator or denominator in determining the percentage of responders who answered each question.

\section{Statistical Analysis}

Data were analyzed using the 1-sample $\chi^{2}$ test, the MannWhitney rank sum test, and the Fisher exact test. Data are presented as mean (SE) where appropriate. For statistical analysis, test statistics with a $P$ value at or less than .05 were considered to be significant.

\section{Results}

Overall, 76 of 155 responses were received, resulting in a $49 \%$ response rate. Among the departments included in the results, the mean (SE) number of faculty was 59 (5), and the median was 50 . Forty-one chairs (54\%) self-reported that they had an "established" mentorship program in their department, while 35 chairs (46\%) felt that while mentoring occurred within their department, it was nonstructured.

Pairing of Mentors and Mentees

In 53 of 76 departments (70\%), the faculty were paired with mentors, with the pairing being either informal (17 of 76, mentee chooses the mentor [22\%]), formal (19 of 76, mentee is assigned to mentor [25\%]), provided by the division chief (15 [20\%]), or via other means (2 [3\%]) (Figure 1). The remaining faculty members (23 [30\%]) did not have a mentor. Of the programs that paired mentors with mentees, 25 of 48 programs (52\%) paired mentees with 1 mentor, while 23 of 48 programs (48\%) paired mentees with 2 or more mentors.
Training for Mentors and Mentees

Sixty-two departments (82\%) offered no official training courses for faculty mentors (Figure 2A). Of the 14 departments that offered training courses for mentors, 3 were offered by the department (21.4\%), 8 were offered by the medical school (57.2\%), and 3 were offered by the university (21.4\%). Seventy-eight percent of programs did not require mentees to attend a career development course (Figure 2B). When required, the career development course was offered by the department ( 6 of 17 departments [35\%]), medical school (7 of 17 departments [41\%]), university (2 of 17 departments [12\%]), or outside of the institution (2 of 17 departments [12\%]).

\section{Commitment to the Relationship}

In almost all departments, neither the mentors (71 [93\%]) nor the mentees (70 [92\%]) were required to sign a mentor or mentee contract. In addition, only 28 departments (37\%) asked mentees to fill out a form stating their short-term and long-term goals on establishing the mentor-mentee relationship. Forty-two programs (55\%) had no formal requirement regarding how often the mentor should meet with the mentee. Of the 34 programs that did have requirements (45\%), 6 required meetings annually (18\%) while 28 required meetings every 3 or 6 months (82\%).

\section{Evaluation of the Mentor-Mentee Relationship}

Only 28 of 76 departments (37\%) required mentors to fill out an evaluation form on the faculty mentee while only 9 departments (12\%) required mentees to fill out an evaluation form on the faculty mentor. When required, the frequency of the requirement to fill out the evaluation form was at least annually for the mentors in 26 of 28 programs (93\%) and annually for the mentees in 7 of 9 programs (78\%). In the 31 departments where evaluation forms were filled out, 28 had evaluation forms reviewed by the chair (90\%), 11 by a division chief (35\%), 6 by a vice chair (19\%), 3 by a mentoring committee (10\%), and surprisingly, 7 by a medical school faculty affairs committee, dean, or vice/associate dean (23\%).

\section{Failed Mentor-Mentee Relationship}

In 70 departments (92\%), no exit strategy (ie, "no-fault divorce" or meeting with the department chair) had been set for failed mentor/mentee relationships (Figure 3). 
Figure 4. Recognition of Faculty Mentoring Efforts

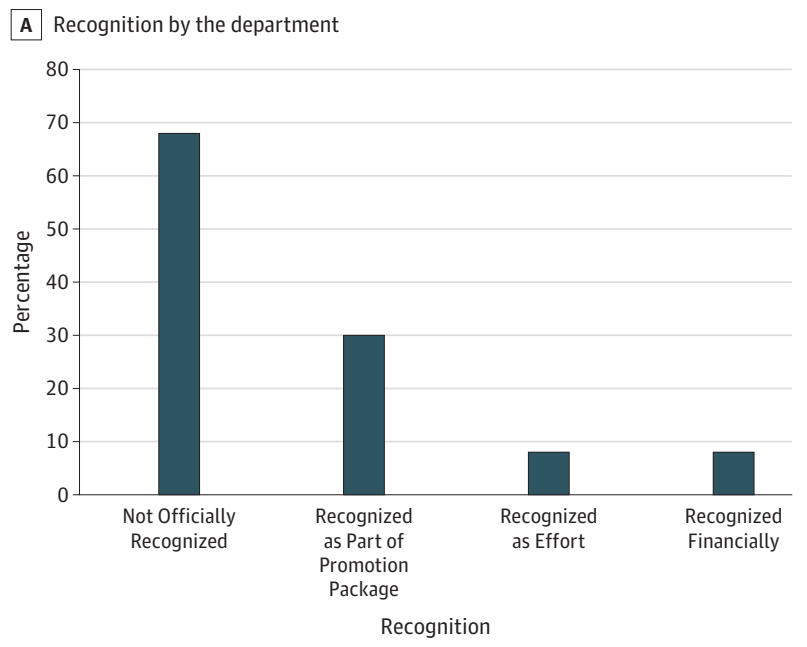

B Recognition by the institution

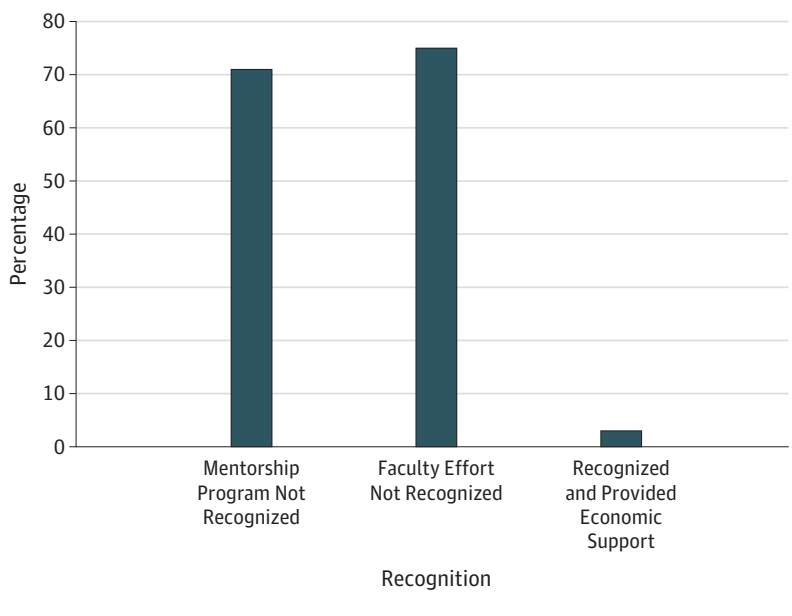

A, Recognition of faculty mentorship activity by the department. B, Recognition of the faculty mentorship programs by the institution.

Recognition of the Mentor-Mentee Relationship

In 52 departments (68\%), the work of the mentor was not officially recognized either financially or academically (Figure 4A). Twenty-three departments (30\%) recognized faculty mentoring activities as part of the promotion package, 6 recognized the effort (ie, time or relative value unit considered in the calculation for overall compensation) (8\%), and 6 recognized it financially (ie, salary or bonus) (8\%). Regarding institutional recognition, most institutions (54 [71\%]) did not recognize the mentorship program within the department of surgery or the effort of the faculty mentors (57 [75\%]) (Figure 4B). Only 2 institutions (3\%) provided economic support for the mentorship program within a department of surgery.

\section{Comparison of Programs With and Without \\ Established Mentorship Programs}

Characteristics of programs that self-identified as having an established mentorship program were compared with programs that self-identified as not having an established mentorship program. Interestingly, programs with established mentorship programs were larger (mean faculty of 70 vs 47 , $P=.02$ ). As would be expected, programs with established mentorship programs were significantly more likely to require mentees to fill out forms stating their short- and long-term goals ( $61 \%$ vs $9 \%, P<.001)$, require a regular frequency of meetings between the mentor and mentee $(73 \%$ vs $11 \%, P=.002)$, require mentors to complete an evaluation form about the mentees ( $63 \%$ vs $6 \%, P=.009$ ), and have the evaluation form reviewed by the department chair (63\% vs $6 \%, P<.001)$. Lastly, programs with established mentorship programs were more likely to be recognized by the institution ( $49 \%$ vs $6 \%, P=.001$ ), and the mentoring activities of the faculty member were more likely to be recognized for academic promotion or by effort (61\% vs $11 \%$, $P=$.004).

\section{Discussion}

Our study shows that approximately half of departments of surgery have established mentorship programs and that, among those that have them, the structure varies significantly. Indeed, while more than two-thirds of departments helped to pair mentors with mentees, less than one-fourth used an informal pairing that allows the mentees to choose their mentors. For most departments, no formal training existed for either the mentor or mentee. Only slightly more than half of departments had requirements for the frequency of scheduled meetings between the mentor and mentee, but most departments did not require the mentor or mentee to fill out evaluation forms about the success of the relationship, nor were exit strategies in place for failed mentor-mentee relationships. Lastly, in most departments, faculty mentoring efforts were not recognized formally by either the department or the institution. These data clearly show that significant variability exists among departments of surgery with respect to the structure of faculty mentorship programs and that active engagement of all 4 key stakeholders is lacking in most of them.

These data have important implications for the career development of academic surgeons. When successful academic physicians are asked about the factors that played a significant role in their career, mentorship is uniformly quoted as a key element. ${ }^{3,4,6,8,12}$ However, review of the literature shows little evidence to support this claim because, to our knowledge, there are no prospective randomized trials comparing the careers of physicians who had mentors with the careers of those who did not, and there are no long-term longitudinal studies assessing the value of mentorship. Even with the lack of prospective data on mentorship, there are several studies that have described the positive effects of mentorship. For instance, in a survey of 4000 mentees in 24 medical schools in the United States, Palepu et $\mathrm{al}^{5}$ found that compared with nonmentored faculty, men- 
tored faculty spent more time on research and were more likely to obtain grants. Other studies have shown a positive effect of mentoring on faculty retention ${ }^{6}$ and scholarship. ${ }^{11}$ In addition, mentorship has been associated with career satisfaction in the areas of career guidance, research productivity, and personal development. ${ }^{3,4}$ For instance, DeCastro et al ${ }^{4}$ surveyed 1708 clinician-researchers between 2010 and 2011 who received National Institutes of Health K08 and K23 career development awards between 2006 and 2009. ${ }^{4}$ Although the study had limitations, such as the self-reported nature of data collection and the fact that the participants had already shown the ability to secure funding from the National Institutes of Health, it identified a correlation between some aspects of mentoring (eg, mentor behavior, mentor prestige, and collegiality of the mentormentee relationship) and career satisfaction. Finally, a report from the University of Toronto has shown that mentoring is also important for promotion, a surrogate for academic success. ${ }^{12}$ In their study, Morrison et $\mathrm{al}^{12}$ examined the time to promotion for faculty before and after implementation of a formal mentorship program and also between mentored and nonmentored faculty regardless of the time to promotion. These authors found that mentorship was independently associated with a reduction in time to promotion. Based on their observation, they concluded that a formal mentoring program supported by the institution has a positive effect on faculty advancement.

Considering the positive effect of mentoring on career satisfaction and possibly on career success, we and others ${ }^{1,6,10,12}$ believe that a mentorship program within a department of surgery should be carefully designed, with the involvement of the 4 key stakeholders (the mentor, the mentee, the department, and the institution) clearly defined. Our study showed that when established mentorship programs were compared with those without a structure, important differences became evident. Specifically, in departments with self-identified mentorship programs, there was more often the involvement of the department in pairing mentors with mentees; the requirement for the mentees to clearly state their short- and longterm goals and to schedule regular meetings; the requirement for the mentor to evaluate the mentee and for the chair to review the evaluation forms; recognition of the mentoring activities for academic promotion; and recognition of the mentoring program by the institution. Similarly, in a review of 18 academic mentoring programs, Kashiwagi et $\mathrm{al}^{1 \mathrm{O}}$ recognized the value of a formal and structured program and identified 7 components that were considered essential for its success: (1) pairing of mentors and mentees; (2) mentor preparation; (3) planning committees; (4) formal curricula; (5) mentor/ mentee contract; (6) mentoring activities; and (7) program funding and participant compensation.

We found that $30 \%$ of faculty were not mentored. Among the $70 \%$ who were mentored, only $22 \%$ of the mentees were able to choose their mentor (ie, informal pairing). This is probably the most successful dyadic relationship because the mentee can select somebody who is knowledgeable, is honest, has experience with the department and the institution, has a wellestablished track record of mentorship, and shares common values. Mentees should be able to choose more than 1 mentor because the health care environment makes it very difficult for
1 mentor to provide adequate guidance for all aspects of an academic career (ie, research, grant writing, clinical activities, participation to academic medical societies). ${ }^{10,16}$ This strategy of having mentees choose their mentors allows mentees "to manage up," a common corporate concept in which the mentee must clearly state his or her needs, must plan and set the meeting agenda, complete assigned tasks, and request feedback. ${ }^{15}$ In our study, $20 \%$ of the mentees were assigned a mentor by the department (ie, formal pairing). We believe this is not an ideal situation because mentees often believe that an assigned mentor is a forced type of relationship and a cause of failure. ${ }^{13}$ For this reason, we believe it is best when the department chair helps the mentee to identify a mentor, supporting a natural, unforced process. The remaining $20 \%$ of faculty members were mentored by the division chief. This relationship can be problematic because it has an inherent imbalance of power and potential conflict of interests and should thereby be managed carefully and with proper oversight to avoid abusive situations. ${ }^{19}$

In most departments, there was no official training for faculty mentors. This may be a problem because while some individuals, particularly those who had effective mentors, are ready to serve this role, others need formal training on how to be a good mentor. Mentoring skills can be taught like any other skill through book reading and attending workshops, seminars, or courses. ${ }^{10}$ The University of California, San Francisco has been a leader in the development of mentorship programs, and this institution has recognized the seminal importance of training mentors through established Mentor Development Programs to be effective teachers, particularly in the area of translational research. ${ }^{1,20}$ Thanks to this program, mentors uniformly reported increased confidence in their mentoring skills such as the ability of helping their mentees in approaching translational research, managing their laboratory, identifying professional goals, building professional collaborations, and understanding the expectations for advancement and promotion. ${ }^{1}$

At the same time, it is essential to provide formal training to the mentees. There are well-established career development courses for residents, fellows, and junior faculty such as the one sponsored by the Association for Academic Surgery. During this course, participants are taught how to choose a mentor, write and revise a manuscript, deliver an effective presentation, prepare an abstract for a national meeting, properly design a study, and statistically analyze the study results. These courses provide essential information for the academic surgeon. For instance, during the Academic Surgical Congress in 2013, the Association for Academic Surgery held a session on "The Art and Science of Publishing," during which the results of a survey of Association for Academic Surgery and Society of University Surgeons members were disseminated. ${ }^{23}$ It was disappointing to discover how many of the respondents did not know about key elements of publishing such as authorship, guest authorship, plagiarism, self-plagiarism, fraud, fabrication, and conflict of interest. ${ }^{23}$ Thus, we believe attending career development courses such as these are beneficial for all mentees pursuing a career in academic surgery.

Regarding commitment to the mentor-mentee relationship, we found that in almost all of the departments, neither 
the mentor nor the mentee were required to sign a contract. This simple document guarantees that both parties in the relationship understand the expectations established in the beginning of the relationship. ${ }^{10}$ In addition, most programs did not require the mentors (63\%) or mentees (88\%) to fill out a form assessing how the relationship was progressing and which goals had been achieved. Monitoring the relationship in regards to personal (eg, respect, punctuality, honesty, and frequency of meetings) and professional (eg, manuscripts, grants, promotion, participation, and leadership positions in national and international societies) aspects of their career is of key importance. ${ }^{2,16,20}$ Another reason routine evaluation of the mentor-mentee relationship should be performed is to determine whether potential areas of conflict are present and whether the relationship is failing. ${ }^{13,14}$ On the part of the mentors, failure is present when the mentee does not perform according to the initial plan or lacks respect. On the part of the mentees, failure is often expressed as the mentor not giving credit to their work, such as taking ownership of research grants, patents, or publications, or focusing on his or her research and not allowing the mentees to explore their own ideas. After careful analysis, if the relationship is deemed failed, an exit strategy, such as a "no-fault divorce," should be implemented. ${ }^{14,24}$ Our study showed that in $92 \%$ of departments, no exit strategy had been set for failed mentormentee relationships. Thus, we believe that evaluation forms should be regularly filled out by both the mentor and the mentee, and they should be reviewed by a mentoring committee and the chair of the department to ensure ongoing successful mentor-mentee relationships.

Our study also shows that most departments and institutions do not recognize or reward the work of the mentor either financially or academically. This is a potential barrier to effective mentoring for the following reasons: (1) the time a mentor dedicates to a mentee is time not spent on his or her own professional and personal activities; (2) mentors are usually senior surgeons who have an increased demand for clinical, research, and administrative tasks; and (3) it takes away an important incentive. Some institutions reward the effort of mentors either financially (eg, relative value units, salary support) or academically (eg, awards for excellence in mentoring, consideration in the promotion application). ${ }^{10-13,16,20}$ For instance, the University of California, San Francisco formally recognizes mentoring as equivalent to teaching in the promotion process, and faculty are required to describe their mentoring activities in the curriculum vitae. ${ }^{20}$ Lastly, we found that only $3 \%$ of institutions provided economic support for the mentorship program within a department of surgery. We believe that an effective mentoring program cannot be established by the chair of the department of surgery without the open and transparent approval and support of the institution. Given the return on investment that the medical school can receive from a formal mentoring program in terms of economic gain (federal and nonfederal grants), program development, national ranking, and particularly retention and recruitment, 6,7,9,14,17 support for these programs should be developed at all institutions.

Our study has some limitations. First, the data obtained in this study were via self-reporting; thus, bias may exist. Second, the survey was entirely anonymous. This limited our ability to track the data back to individual institutions and perform additional analyses such as the impact on extramural funding, publications, retention, promotion, private vs public institution, safety-net burden of the hospital, and term of the chair of surgery. Third, while we achieved a response rate of nearly $50 \%$, the data in this article are not representative of all 155 departments across the United States. A response bias may exist such that chairs of departments of surgery with more structured mentorship programs were more inclined to answer the survey. Fourth, these data are survey data representing a single point in time and do not reflect longitudinal data on the effect of a mentorship program on the career development of faculty. Even with these limitations, we believe the data presented herein provide meaningful insights into the nature of mentorship programs.

\section{Conclusions}

Our data show that the presence and structure of mentorship programs in departments of surgery across the United States are highly variable with respect to the pairing of mentors with mentees, commitment to the relationship, training provided, and recognition by all 4 key stakeholders. Because mentorship has been shown to be one of the most important factors for career satisfaction (and possibly success), development and maintenance of an established faculty mentorship program with the involvement of the department and the institution may lead to greater faculty satisfaction, productivity, and retention.

\section{ARTICLE INFORMATION}

Accepted for Publication: March 25, 2016.

Published Online: July 6, 2016. doi:10.1001/jamasurg.2016.1670

Author Contributions: Dr Patti had full access to all the data in the study and takes responsibility for the integrity of the data and the accuracy of the data analysis.

Study concept and design: Kibbe, Pellegrini, Townsend, Patti.

Acquisition, analysis, or interpretation of data: Kibbe, Helenowski, Patti.

Drafting of the manuscript: Kibbe, Pellegrini, Patti.
Critical revision of the manuscript for important intellectual content: Kibbe, Townsend, Helenowski, Patti.

Statistical analysis: Kibbe, Helenowski. Administrative, technical, or material support: Kibbe, Pellegrini, Townsend.

Study supervision: Kibbe, Patti.

Conflict of Interest Disclosures: None reported.

Disclaimer: Dr Kibbe is the Editor of JAMA Surgery but was not involved in the editorial review or the decision to accept the manuscript for publication.
Previous Presentation: This manuscript was presented at the annual meeting of the American College of Surgeons; October 6, 2015; Chicago, Illinois.

Additional Contributions: We thank Kayla Dangerfield, Northwestern University, for her editorial review of the manuscript.

\section{REFERENCES}

1. Feldman MD, Huang L, Guglielmo BJ, et al. Training the next generation of research mentors: the University of California, San Francisco, Clinical 
and Translational Science Institute Mentor Development Program. Clin Trans/ Sci. 2009;2(3): 216-221.

2. Anderson L, Silet K, Fleming M. Evaluating and giving feedback to mentors: new evidence-based approaches. Clin Trans/ Sci. 2012;5(1):71-77.

3. Wasserstein AG, Quistberg DA, Shea JA. Mentoring at the University of Pennsylvania: results of a faculty survey. J Gen Intern Med. 2007;22(2): 210-214.

4. DeCastro R, Griffith KA, Ubel PA, Stewart A, Jagsi R. Mentoring and the career satisfaction of male and female academic medical faculty. Acad Med. 2014;89(2):301-311.

5. Palepu A, Friedman RH, Barnett RC, et al. Junior faculty members' mentoring relationships and their professional development in U.S. medical schools. Acad Med. 1998;73(3):318-323.

6. Ries A, Wingard D, Gamst A, Larsen C, Farrell E, Reznik $\mathrm{V}$. Measuring faculty retention and success in academic medicine. Acad Med. 2012;87(8):1046 1051.

7. Alexander $\mathrm{H}$, Lang J. The Long-term Retention and Attrition of US Medical School Faculty. Washington, DC: AAMC; 2008:8

8. Powell DW. Mentoring: then and now. Gastroenterology. 2014;147(3):550-553.

9. Bucklin BA, Valley M, Welch C, Tran ZV, Lowenstein SR. Predictors of early faculty attrition at one Academic Medical Center. BMC Med Educ. 2014;14:27.
10. Kashiwagi DT, Varkey P, Cook DA. Mentoring programs for physicians in academic medicine: a systematic review. Acad Med. 2013;88(7):1029 1037.

11. Sambunjak D, Straus SE, Marusić A. Mentoring in academic medicine: a systematic review. JAMA 2006;296(9):1103-1115.

12. Morrison LJ, Lorens E, Bandiera G, et al; Faculty Development Committee, Department of Medicine Faculty of Medicine, University of Toronto. Impact of a formal mentoring program on academic promotion of Department of Medicine faculty: a comparative study. Med Teach. 2014;36(7):608 614

13. Straus SE, Chatur F, Taylor M. Issues in the mentor-mentee relationship in academic medicine: a qualitative study. Acad Med. 2009;84(1):135-139.

14. Straus SE, Johnson MO, Marquez C, Feldman MD. Characteristics of successful and failed mentoring relationships: a qualitative study across two academic health centers. Acad Med. 2013;88 (1):82-89.

15. Zerzan JT, Hess R, Schur E, Phillips RS, Rigotti N. Making the most of mentors: a guide for mentees. Acad Med. 2009;84(1):140-144.

16. Keyser DJ, Lakoski JM, Lara-Cinisomo S, et al. Advancing institutional efforts to support research mentorship: a conceptual framework and self-assessment tool. Acad Med. 2008;83(3):217-225.

17. Pololi LH, Evans AT, Civian JT, et al. Mentoring faculty: a US national survey of its adequacy and linkage to culture in academic health centers. J Contin Educ Health Prof. 2015;35(3):176-184.

18. Pfund $C$, House SC, Asquith $P$, et al. Training mentors of clinical and translational research scholars: a randomized controlled trial. Acad Med. 2014;89(5):774-782.

19. Pololi L, Knight S. Mentoring faculty in academic medicine: a new paradigm? J Gen Intern Med. 2005;20(9):866-870.

20. Johnson MO, Subak LL, Brown JS, Lee KA, Feldman MD. An innovative program to train health sciences researchers to be effective clinical and translational research mentors. Acad Med. 2010;85 (3):484-489

21. Strong EA, De Castro R, Sambuco D, et al. Work-life balance in academic medicine: narratives of physician-researchers and their mentors. J Gen Intern Med. 2013;28(12):1596-1603.

22. Blixen CE, Papp KK, Hull AL, Rudick RA, Bramstedt KA. Developing a mentorship program for clinical researchers. J Contin Educ Health Prof. 2007:27(2):86-93.

23. Kibbe MR, Sarr MG, Livingston EH, Freischlag JA, Lillemoe KD, McFadden DW. The art and science of publishing: reflections from editors of surgery journals. J Surg Res. 2014;186(1):7-15.

24. Sanfey H, Hollands C, Gantt NL. Strategies for building an effective mentoring relationship. Am J Surg. 2013;206(5):714-718. 